\title{
BMJ Open Assessing variation among the national essential medicines lists of 21 high- income countries: a cross-sectional study
}

Michael Sergio Taglione (ib ,1,2 Nav Persaud (id) 1,3

To cite: Taglione MS, Persaud N. Assessing variation among the national essential medicines lists of 21 highincome countries: a crosssectional study. BMJ Open 2021;11:e045262. doi:10.1136/ bmjopen-2020-045262

- Prepublication history for this paper is available online. To view these files, please visit the journal online (http://dx.doi org/10.1136/bmjopen-2020045262).

Received 30 September 2020 Accepted 20 July 2021

\section{Check for updates}

(c) Author(s) (or their employer(s)) 2021. Re-use permitted under CC BY-NC. No commercial re-use. See rights and permissions. Published by BMJ.

${ }^{1}$ Department of Family and Community Medicine, University of Toronto Faculty of Medicine, Toronto, Ontario, Canada ${ }^{2}$ Department of Family and Community Medicine, North York General Hospital, Toronto, Ontario, Canada

${ }^{3}$ Centre for Urban Health Solutions, St Michael's Hospital, Toronto, Ontario, Canada

Correspondence to Dr Michael Sergio Taglione; mike.s.taglione@gmail.com

\section{ABSTRACT}

Objective Essential medicines lists have been created and used globally in countries that range from low-income to high-income status. The aim of this paper is to compare the essential medicines list of high-income countries with each other, the WHO's Model List of Essential Medicines and the lists of countries of other income statuses. Design High-income countries were defined by World Bank classification. High-income essential medicines lists were assessed for medicine inclusion and were compared with the subset of high-income countries, the WHO's Model List and 137 national essential medicines lists. Medicine lists were obtained from the Global Essential Medicines database. Countries were subdivided by income status, and the groups' most common medicines were compared. Select medicines and medicine classes were assessed for inclusion among high-income country lists.

Results The 21 high-income countries identified were most like each other when compared with other lists. They were more like upper middle-income countries and least like low-income countries. There was significant variability in the number of medicines on each list. Less than half (48\%) of high-income countries included a newer diabetes medicines in their list. Most countries (71\%) included naloxone while every country including at least one opioid medicine. More than half of the lists $(52 \%)$ included a medicine that has been globally withdrawn or banned. Conclusion Essential medicines lists of high-income countries are similar to each other, but significant variations in essential medicine list composition and specifically the number of medications included were noted. Effective medicines were left off several countries' lists, and globally recalled medicines were included on over half the lists. Comparing the essential medicines lists of countries within the same income status category can provide a useful subset of lists for policymakers and essential medicine list creators to use when creating or maintaining their lists.

\section{INTRODUCTION}

Essential medicines lists (EMLs) contain medicines deemed necessary in addressing the priority healthcare needs of a population. ${ }^{1}$ The WHO has created and maintained a Model List of Essential Medicines as a guide for developing national EMLs with an aim of improving access, quality and rational use of medicines globally. ${ }^{1}$ To date, at least 137

\section{Strengths and limitations of this study}

This is the first study to evaluate and compare the essential medicines lists of a subset of countries based on income status.

- The Global Essential Medicines database was published in 2019 and is the most up-to-date repository of essential medicines lists publicly available.

- The analysis is subject to the database's limitations, including outdated information, coding errors and information limited to medication name, country and WHO List of Essential Medicines inclusion.

- The analysis performed does not account for national or subnational drug coverage policies, the utilisation of essential medicines lists within those policies nor the conflict-of-interest policies in developing the respective essential medicine lists.

countries worldwide have developed their own national EMLs, aiming to include medicines that are efficacious, safe and sustainable. $^{2}$ Substantial numbers of differences between countries in the included medicines are only partially explained by country characteristics. ${ }^{12}$ Perhaps it should be expected given the unique challenges faced in each respective country, but it may represent the inclusion of inappropriate medicines or exclusion of essential medicines on national essential medicines lists around the globe.

Countries can be divided into four income status categories per World Bank classification: high income, upper middle income, lower middle income and low income. ${ }^{3}$ Countries that fall in the high-income category face different medicine access challenges when compared with countries in the low-income category. For example, the availability of insulin in pharmacies across countries with different income status ranged significantly. Insulin was available in $94 \%$ of pharmacies in high-income countries, $40 \%$ in upper middleincome countries, $29 \%$ in lower middleincome countries and $10 \%$ of pharmacies in lower income countries. ${ }^{4}$ 
The essential medicines concept is relevant to highincome countries and may help to both ensure appropriate medicine selection and, when combined with broader policies, better medicine access. ${ }^{56}$ For example, the number of high-cost patented medicines on the market in Canada increased more than 200\% from 2006 to 2017 , all while 1 in 10 Canadians (approximately 3.5 million people) could not afford their prescription drugs. ${ }^{78}$ This paper aims to analyse and compare highincome countries with national EMLs to evaluate differences between this group, the WHO Model's List of Essential Medicines and other countries with national EMLs. Beyond the broad evaluation, specific medicine classes and medicines were assessed for inclusion and exclusion among the high-income EMLs.

\section{METHODS}

Inclusion criteria for the analysis were: (1) the country meets the World Bank definition of a high-income country and (2) the country has a national essential medicines list documented in the Global Essential Medicines database of 137 national essential medicines lists.

High-income countries were defined according to the 2019 World Bank criteria that indicate high-income countries are those with a gross national income per capita, calculated using the World Bank Atlas method, greater than $\$ 12376 .{ }^{3}$ The gross national income per capita obtained from the World Bank is calculated using the Atlas Method. ${ }^{3}$

The Global Essential Medicines database was published in 2019 and is a freely accessible repository of 137 national essential medicines lists registered with the WHO. The database provides a list of countries with an EML, the medicines on each EML, the most recent year of the EML's publication and indicates if a medication is included on the WHO List of Essential Medicines. ${ }^{2}$

\section{Patient and public involvement}

Given the research design focusing on an analysis of a publicly available database, patients and the public were not involved in the design, conduct or analysis of this research.

\section{Data collection process}

Twenty-one countries met both inclusion criteria. The medicines for each countries' EML were extracted from the database into an Excel spreadsheet for comparison.

The following characteristics of each included country were collected: WHO region; population size; life expectancy; infant mortality; gross domestic product (GDP) per capita; gross national income per capita; the current health care expenditure per capita; and the Healthcare Access and Quality (HAQ) Index Score. Data on WHO Regions and per capita healthcare expenditure was obtained from the WHO Global Health Observatory. ${ }^{9}$ We extracted data on population, life expectancy, infant mortality and GDP per capita from the Central
Intelligence Agency's World Factbook. ${ }^{10}$ We extracted the gross national income per capita from the World Bank. ${ }^{11}$ The HAQ Index Score for each country was extracted from the original manuscript. ${ }^{12}$

\section{Data analysis}

Essential medicine list comparisons by country

The EMLs of each country were compared with the 2017 WHO's Model List of Essential Medicines to identify the number of medicines on the WHO's Model List not included on a country's list and to identify the number of medicines on a country's list not included on the WHO's Model List. ${ }^{13}$

High-income countries were also compared with each other for differences in commonly included and excluded medicines. Lists were reviewed to identify the number of medicines on a country's EML that less than $50 \%$ of high-income countries included on their EMLs and the number of medicines not on a country's EML that greater than $50 \%$ of high-income countries included on their EMLs.

Similarity scores were calculated to compare the EMLs. The methodology described by Persaud et $a l^{2}$ was used: 'To calculate a similarity score, we divided medicines into those that are commonly listed (by at least $50 \%$ of countries) and those that are uncommonly listed (by less than $50 \%$ of countries). For each country's list we calculated the score by counting the medicines on that list that are commonly listed and subtracting the number of uncommonly listed medicines. This calculation provides a similarity integer score for each country; positive scores indicate that most medicines in the country's list are commonly listed in other countries' lists, and negative scores indicate that most medicines are uncommonly listed in other countries' lists'. The similarity scores for each high-income country were calculated using the subset of 21 high-income countries and the database's repository of 137 countries.

High-income countries compared with countries of other income status

We compared the most commonly included medicines on high-income countries' EMLs with those of upper middle income, lower middle income and low income. The gross national income per capita of upper middle, lower middle and low income countries were \$3996-\$12 $375, \$ 1026-\$ 3995$ and $<\$ 1026$, respectively. ${ }^{3}$ Common medicines were defined as those included on greater than $80 \%$ of countries' EMLs within a specific income status category.

\section{Select medicines and medicine class analysis}

To better understand the trends, similarities and differences among the EMLs, we compared select medicines and medicine classes. Additionally, the EMLs of each high-income country were assessed for the inclusion of any of 11 globally recalled medicines. ${ }^{14}$ 
Table 2 High-income country EMLs compared with the who model list and with high-income countries commonly included medications

\begin{tabular}{|c|c|c|c|c|c|c|c|}
\hline Country & $\begin{array}{l}\text { Total } \\
\text { medications } \\
\text { on list }\end{array}$ & $\begin{array}{l}\text { Medications on } \\
\text { country EML but } \\
\text { not WHO model } \\
\text { list }\end{array}$ & $\begin{array}{l}\text { Medications on } \\
\text { WHO model list } \\
\text { but not country } \\
\text { EML }\end{array}$ & $\begin{array}{l}\text { Total } \\
\text { differences } \\
\text { between } \\
\text { country and } \\
\text { WHO EML }\end{array}$ & $\begin{array}{l}\text { Medications } \\
\text { on country } \\
\text { EML but } \\
\text { on }<50 \% \text { of } \\
\text { high-income } \\
\text { EMLs }\end{array}$ & $\begin{array}{l}\text { Medications } \\
\text { on }>50 \% \text { of } \\
\text { high-income } \\
\text { EMLs but not } \\
\text { on country } \\
\text { EML }\end{array}$ & $\begin{array}{l}\text { Total } \\
\text { differences } \\
\text { between } \\
\text { country } \\
\text { EML and } \\
\text { high-income } \\
\text { majority }\end{array}$ \\
\hline $\begin{array}{l}\text { Antigua and } \\
\text { Barbuda }\end{array}$ & 292 & 99 & 176 & 275 & 63 & 180 & 243 \\
\hline Barbados & 625 & 389 & 124 & 513 & 264 & 48 & 312 \\
\hline Chile & 349 & 140 & 162 & 302 & 96 & 156 & 252 \\
\hline Croatia & 599 & 346 & 114 & 460 & 260 & 70 & 330 \\
\hline Czech Republic & 802 & 568 & 133 & 701 & 434 & 41 & 475 \\
\hline Malta & 607 & 385 & 144 & 529 & 278 & 80 & 358 \\
\hline Oman & 576 & 303 & 96 & 399 & 231 & 64 & 295 \\
\hline Palau & 268 & 114 & 215 & 329 & 83 & 224 & 307 \\
\hline Poland & 441 & 287 & 214 & 501 & 169 & 137 & 306 \\
\hline Portugal & 905 & 674 & 136 & 810 & 546 & 50 & 596 \\
\hline $\begin{array}{l}\text { Saint Kitts and } \\
\text { Nevis }\end{array}$ & 290 & 100 & 180 & 280 & 61 & 180 & 241 \\
\hline Seychelles & 294 & 102 & 176 & 278 & 67 & 182 & 249 \\
\hline Slovakia & 983 & 722 & 103 & 825 & 601 & 27 & 628 \\
\hline Slovenia & 787 & 524 & 97 & 621 & 418 & 40 & 458 \\
\hline
\end{tabular}

EMLs, essential medicines lists.

\section{RESULTS}

Of the 79 countries that had a gross national income per capita that met the definition of high-income status, 21 (26.6\%) had an EML documented in the Global Essential Medicines database. ${ }^{3}$ Most of these countries were in the European and Americas WHO region. The included countries had similar life expectancies but varied significantly with respect to their population size, infant mortality, gross domestic product and current health expenditure per capita (table 1). The HAQ Index scores ranged from 62 to 90 among countries, with European countries averaging the highest score of 82.6, Eastern Mediterranean countries averaging 78 , countries from the Americas with 68.8 and one African country scoring 66 . The correlation between HAQ scores and number of medications on an EML was poor with a $R^{2}$ value of 0.1186 . The countries also varied in their EML's publication year, with the most recent list updated in 2017 and the oldest list published in 2005 .

\section{EMLs comparisons by country}

There were large differences among many high-income EMLs when compared directly to the WHO's Model List of Essential Medicines (table 2). Four countries had more than 500 medicines added to their lists not on the WHO's Model List (Czech Republic, Portugal, Slovakia and Slovenia). Six countries had more than 200 medicines excluded from their list recommended by the WHO (Estonia, Latvia, Lithuania, Palau, Poland and Sweden). High-income countries ranged from 275 to 825 difference from the WHO's Model List. The number of differences decreased when comparing individual highincome EMLs with medicines included on more than half of the high-income country lists. Only two countries had more than 500 less common medicines added to their list (Portugal and Slovakia), and two had greater than 200 medicines excluded from their list that were include on more than half of other high-income EMLs (Palau and Sweden). 
Table 3 Similarity scores of high-income countries calculated by subset of 21 high-income countries and full database of 137 countries

\begin{tabular}{|c|c|c|c|c|c|c|}
\hline Countries & $\begin{array}{l}\text { Total medications } \\
\text { on list }\end{array}$ & $\begin{array}{l}\text { Medications } \\
\text { on }>50 \% \text { of high } \\
\text { income lists }\end{array}$ & $\begin{array}{l}\text { Medications } \\
\text { on }<50 \% \text { of high } \\
\text { income lists }\end{array}$ & $\begin{array}{l}\text { Similarity score } \\
\text { among } 21 \\
\text { high income } \\
\text { countries }\end{array}$ & $\begin{array}{l}\text { Similarity score } \\
\text { among } 137 \\
\text { countries }^{(2)}\end{array}$ & $\begin{array}{l}\text { Delta similarity } \\
\text { score between } \\
\text { high income group } \\
\text { and all countries }\end{array}$ \\
\hline Bahrain & 550 & 338 & 212 & 126 & -106 & 232 \\
\hline Barbados & 625 & 361 & 264 & 97 & -159 & 256 \\
\hline Czech Republic & 802 & 368 & 434 & -66 & -398 & 332 \\
\hline Estonia & 405 & 268 & 137 & 131 & -141 & 272 \\
\hline Latvia & 304 & 223 & 81 & 142 & -96 & 238 \\
\hline Lithuania & 339 & 262 & 77 & 185 & -77 & 262 \\
\hline Portugal & 905 & 359 & 546 & -187 & -497 & 310 \\
\hline Saint Kitts and Nevis & 290 & 229 & 61 & 168 & 140 & 28 \\
\hline Seychelles & 294 & 227 & 67 & 160 & 114 & 46 \\
\hline Slovakia & 983 & 382 & 601 & -219 & -553 & 334 \\
\hline Slovenia & 787 & 369 & 418 & -49 & -359 & 310 \\
\hline Sweden & 289 & 191 & 98 & 93 & -61 & 154 \\
\hline Trinidad and Tobago & 493 & 330 & 163 & 167 & -41 & 208 \\
\hline Uruguay & 518 & 337 & 181 & 156 & -106 & 262 \\
\hline
\end{tabular}

The similarity scores of every high-income country increased when compared with only high-income countries rather than the 137 countries included in the database (table 3 ). Whereas only 5 of the 21 high-income countries had positive similarity scores when comparing to all 137 countries, 17 had positive scores when comparing to the 21 high-income countries. Similarity scores increased an average of 208 points, with a minimum increase of 26 and maximum increase of 334 .

\section{High-income countries compared with countries of other income levels}

There were 136 medicines that were listed on greater than $80 \%$ of the group of 21 high-income countries' EMLs (table 4). The 48 upper middle-income, 40 lower middle-income and 28 low-income countries had 114, 128 and 134 medicines on over $80 \%$ of the lists within their respective income status categories. Comparing the highincome countries list with the other income status categories showed that the upper middle-income countries list had $66.9 \%$ of the medicines included on the high-income list, the lower middle-income countries had $58.8 \%$ of the medicines included on the high-income list and the lowincome countries had $55.1 \%$ of the medicines included on the high-income list. The high-income country medicines that were present on the other income country lists represented $79.8 \%, 62.5 \%$ and $56.0 \%$ of the total number of medicines on the upper middle, lower middle and lowincome country lists, respectively.

\section{Selected medicine and medicine class analysis}

Select medicines and medicine classes were assessed for inclusion or exclusion on each high-income country's EML as well as the WHO's Model List. Among newer diabetes medicines, 9 of 21 countries had a DPP4 inhibitor and 8 of 21 had a GLP1 agonist. No countries included an SGLT2 inhibitor, although only four lists had been revised since SGLT2 inhibitors became available in 2012. ${ }^{15}$ Despite being listed on the WHO's Model List, only 11 of 21 countries included hepatitis $\mathrm{C}$ medicines. Since the availability of direct oral anticoagulants in 2008 , only 9 of 16 countries have added them to their lists. ${ }^{16}$ For higher cost medicines, 11 countries included a Tumor Necrosis Factor (TNF) inhibitor (eg, infliximab, brand name Remicade) and nine included a monoclonal antibody (eg, adalimumab, brand name Humira).

With respect to medicines used in the management of substance use disorders, 8 countries included alcohol cessation medicines and five included smoking cessation medicines. All 21 countries had an opioid on their list, but only 16 had opioid cessation medicines listed. 15 high-income countries had the opioid overdose reversal agent naloxone included on their lists. 


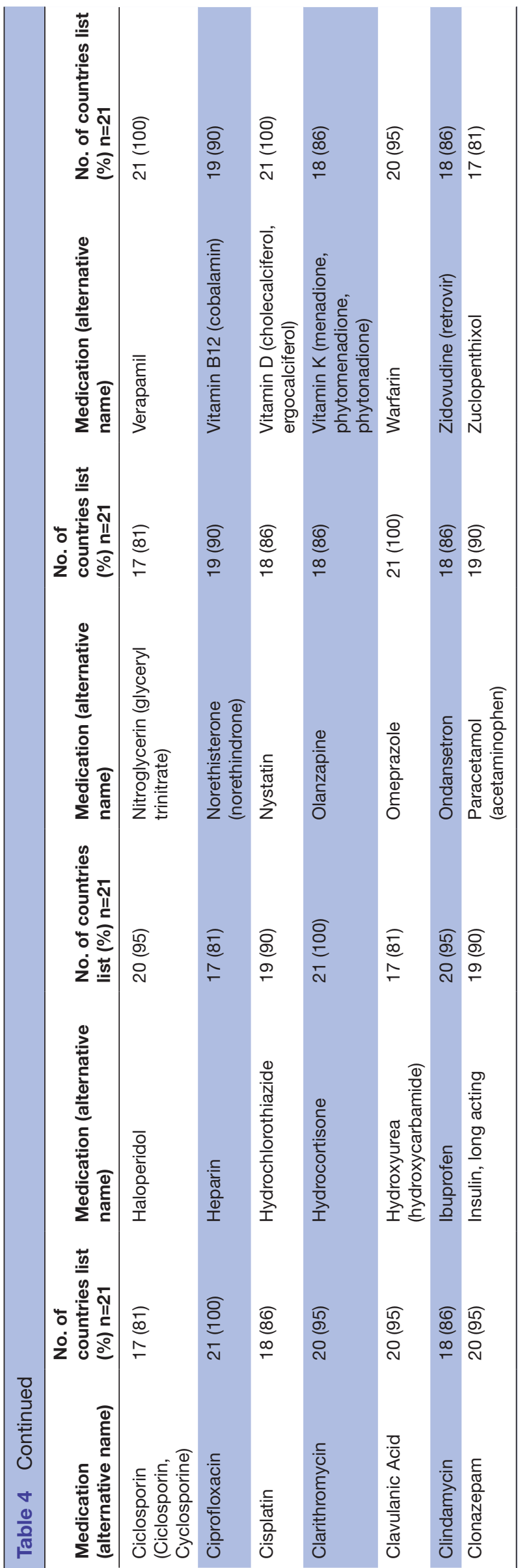

Of the eleven globally withdrawn medicines, six were present on at least one of the high-income countries' EMLs and 11 of the 21 high-income countries had at least one globally withdrawn medicine on their essential medicines list. The only medicine present on more than one list was thioridazine, which was withdrawn globally in 2005. It was present on a third of the high-income countries' EMLs. The specific medicines withdrawn are presented in table 5 .

\section{DISCUSSION}

Only about one-quarter of high-income countries had a national EML, despite the associated improvements seen with EML use in prescribing practices and medication access. ${ }^{56}$ The countries also demonstrated a large range in publication year with a median publication year of 2011. Some of these countries may not have updated their EML because they do not use it in their national drug policy. Alternatively, the database may have included an outdated list.

The national EMLs of the 21 high-income countries differed greatly from the WHO's Model List of Essential Medicines. The individual high-income countries were more similar to each other when compared with countries with smaller economies. However, four countries (Czech Republic, Portugal, Slovakia and Slovenia) stood out with negative similarity scores when comparing among highincome countries, indicating the presence of outliers within the high-income group. A negative similarity score indicates that the majority of a country's EML is made up of medicines not on included on at least $50 \%$ of its high-income peer countries' EMLs. These four countries had the four largest EMLs within the high-income group and each included at least 50\% more medicines than the high-income country average of 510 medicines. Each country has unique needs and is encouraged by the WHO to adapt their EMLs to address those needs, but outliers within similar income classes may represent opportunities for further evaluation and list refinement. ${ }^{1}$ These outlier EMLs are likely a result of overinclusion of medicines that other high-income countries do not deem essential. All countries, and specifically the four outlier countries, should reassess the medicines on their EMLs frequently and remove any medicines found to be ineffective, inappropriate or unsafe.

The income group analysis demonstrated that a relationship exists between income class and the medicines included on a country's EML. High-income countries were most similar to upper middle-income countries, somewhat similar to low middle-income countries and least similar to low-income countries. This may be explained by the differing medical needs of those living in developed and developing nations. For example, $95 \%$ of high-income countries include atorvastatin to treat high cholesterol, whereas only $60 \%$ of upper middle-income, $38 \%$ of low middle-income and $25 \%$ of low-income countries include it. Conversely, the antiparasitic medicine niclosamide is 
Table 5 Medicines withdrawn worldwide included in one or more high-income country list

\begin{tabular}{|c|c|c|c|c|c|c|c|c|c|}
\hline \multirow[b]{2}{*}{ Country } & \multirow{2}{*}{$\begin{array}{l}\text { Total } \\
\text { medications } \\
\text { on list }\end{array}$} & \multirow[b]{2}{*}{$\begin{array}{l}\text { EML year of } \\
\text { publication }\end{array}$} & \multirow{2}{*}{$\begin{array}{l}\text { Total number } \\
\text { of withdrawn } \\
\text { medications } \\
\text { on country } \\
\text { EML }\end{array}$} & \multicolumn{6}{|c|}{$\begin{array}{l}\text { Medications withdrawn worldwide } \\
\text { (Year of withdrawal) }\end{array}$} \\
\hline & & & & $\begin{array}{l}\text { Astemizole } \\
\text { (1999) }\end{array}$ & $\begin{array}{l}\text { Drotrecogin } \\
\text { (2011) }\end{array}$ & $\begin{array}{l}\text { Laropiprant } \\
\text { (2013) }\end{array}$ & $\begin{array}{l}\text { Nebacumab } \\
\text { (1993) }\end{array}$ & $\begin{array}{l}\text { Terodiline } \\
\text { (1992) }\end{array}$ & $\begin{array}{l}\text { Thioridazine } \\
\text { (2005) }\end{array}$ \\
\hline $\begin{array}{l}\text { Antigua \& } \\
\text { Barbuda }\end{array}$ & 292 & 2008 & 1 & & & & & & Included \\
\hline Bahrain & 550 & 2015 & 1 & & & & Included & & \\
\hline Croatia & 599 & 2010 & 0 & & & & & & \\
\hline Czech Republic & 802 & 2012 & 0 & & & & & & \\
\hline Estonia & 405 & 2012 & 0 & & & & & & \\
\hline Latvia & 304 & 2012 & 0 & & & & & & \\
\hline Lithuania & 339 & 2012 & 0 & & & & & & \\
\hline Poland & 441 & 2017 & 0 & & & & & & \\
\hline Portugal & 905 & 2011 & 1 & & & Included & & & \\
\hline $\begin{array}{l}\text { Saint Kitts and } \\
\text { Nevis }\end{array}$ & 290 & 2007 & 1 & & & & & & Included \\
\hline Seychelles & 294 & 2010 & 0 & & & & & & \\
\hline Slovakia & 983 & 2012 & 1 & Included & & & & & \\
\hline Slovenia & 787 & 2017 & 1 & & & & & Included & \\
\hline Sweden & 289 & 2016 & 0 & & & & & & \\
\hline $\begin{array}{l}\text { Trinidad and } \\
\text { Tobago }\end{array}$ & 493 & 2010 & 1 & & & & & & Included \\
\hline
\end{tabular}

included on more than $80 \%$ of the low-income countries' EMLs but on only $10 \%$ of high-income country lists. Comparing countries with similar resources as measured through their income status categorisation may allow for more granular comparisons that can better identify areas for improvement. The similarity seen among the highincome countries suggests that income status categorisation defined by World Bank standards can be used for further subset analysis countries with essential medicines lists.

Although high-income EMLs are similar on broad review, potential areas for improvement can still be identified within the group. The newest oral diabetes medicine, SGLT2 inhibitors, has clinical evidence indicating its use reduces the risk of major cardiovascular events and slows the progression of renal disease. ${ }^{17}$ However none of the four countries with recently revised EMLs have added it their lists, nor has the WHO added it to the Model List of Essential Medicines as of 2019. ${ }^{18}$ Similarly, only 9 of the 16 countries with updated EMLs since 2008 include direct oral anticoagulants that do not require ongoing bloodwork for therapeutic monitoring like warfarin. ${ }^{19}$ Aside from clinical efficacy, there were safety concerns within some high-income EMLs. Despite the inclusion of opioid medicines on all 21 lists, the opioid antidote naloxone that can reverse overdoses was only present on
15 , representing a deficiency in public health efforts to respond to an increase in opioid-related deaths. Additionally, over half of high-income countries included globally recalled medicines with significant safety concerns, illustrating the importance of ongoing evaluations of EMLs for removal of unsafe or ineffective medicines. ${ }^{14}$ These findings underscore the need to update EMLs regularly. The WHO updates the Model List of Essential Medicines every 2 years and countries could update their own EMLs at a similar frequency. ${ }^{13}$

Comparing high-income countries by medicine or medicine class highlights the differences that can be present among the EMLs of similar countries. These differences may be intentional to address specific country needs, or they may represent decisions that should be re-evaluated. It is not the purpose of this paper to focus on a specific country but instead aims to encourage countries to refine their list using all available data, including peer countries' EMLs.

The medication coverage policies of each high-income country with an EML were sought out from publicly available information. Policies ranged from free medicines on the EML at the point of service to fixed or percentagebased copays. ${ }^{20-22}$ However, many countries did not specify the role of EMLs in their policy and others did not have any publicly available information describing 
their national drug coverage policy. Given the incomplete information, it was not further analysed.

Beyond potential influence on national and subnational medication coverage policies, clinical benefits can be derived from EML use. Sweden, for example, has used their Wise List EML to improve prescribing practices of commonly used medications. ${ }^{23}$ Over a 15 -year period, Wise List recommendations aimed at improving clinical decision making and cost-effective prescribing in Stockholm improved to $84 \%$ recommendation adherence, representing a 9\% improvement. Strategic use of an evidence-based and transparently constructed EML can have major impacts on downstream prescribing practices.

To our knowledge, this is the first study comparing the essential medicines lists of high-income countries. The analysis depended on medicine data from the Global Essential Medicines database and thus is subject to the database's limitations, including outdated information and coding errors. The database includes only medication name, country's name and inclusion on the WHO List of Essential Medicines, and thus more robust data including generic status, dosages and prescribing patterns were unavailable. Expanding the database to include this information as well as a country's EML changes over time would be beneficial in providing more detailed analysis. Furthermore, the analysis performed does not account for national or subnational drug coverage policies or the utilisation of EMLs within those policies. We did not have information about potential conflict of interest for EML selection committee members or about procedures for handling conflicts of interest in EML development, and such conflicts could have negatively influenced medicine selection. ${ }^{24}$ We attempted to obtain the drug coverage policies and use of EMLs of the 21 high-income countries but that information was not publicly available for many countries. Future research is needed to compare EML drug coverage policies and evaluate the impact of factors that can influence which medicines are included or excluded on a given country's EML. Conflict-of-interest policies and generic availability likely play a significant role in EML list construction and further work to characterise their respective influence is warranted. We focused on national EML, but subnational medicines lists are also important. ${ }^{23}$

EMLs of high-income countries are relatively similar to each other when comparing with countries of other income status. However, specific EML and medicine level analysis of high-income countries allowed for relevant differences to be identified and areas for improvement highlighted. Countries can improve their EMLs by using the global database to compare their list with the lists of their peer countries. By doing so they can identify medicines that should be added to or removed from their own lists. Grouping countries by income status proved to provide a cohort of similar countries that had notable differences and areas for improvement. Future subgroup analysis of the other income groups should be performed to provide more specific insight as those countries continue to revise and improve their own lists. Furthermore, countries without national essential medicines lists should use the Global Essential Medicines database in conjunction with the WHO's Model List of Essential Medicines to construct a list for use in their national medicine coverage policy.

Acknowledgements NP is supported by the Department of Family and Community Medicine, St Michael's Hospital and the Department of Family and Community Medicine, University of Toronto, Canada, which is designated the WHO Collaborating Centre on Family Medicine and Primary Care.

Contributors MST and NP developed the study design. MST performed the analysis as described in the methodology. MST and NP interpreted the data and cowrote the manuscript. Both authors approved the final draft prior to journal submission.

Funding This work was supported by grants from the Canadian Institutes of Health Research and the Ontario Strategy for Patient Oriented Research Support Unit.

Competing interests None declared.

Patient and public involvement Patients and/or the public were not involved in the design, or conduct, or reporting, or dissemination plans of this research.

Patient consent for publication Not required.

Provenance and peer review Not commissioned; externally peer reviewed.

Data availability statement Data are available in a public, open access repository.The Global Essential Medicines database is available at https://global. essentialmeds.org.

Open access This is an open access article distributed in accordance with the Creative Commons Attribution Non Commercial (CC BY-NC 4.0) license, which permits others to distribute, remix, adapt, build upon this work non-commercially, and license their derivative works on different terms, provided the original work is properly cited, appropriate credit is given, any changes made indicated, and the use is non-commercial. See: http://creativecommons.org/licenses/by-nc/4.0/.

\section{ORCID iDs}

Michael Sergio Taglione http://orcid.org/0000-0001-8080-7282

Nav Persaud http://orcid.org/0000-0003-3327-5580

\section{REFERENCES}

1 World Health Organization. Essential medicines. Geneva, 2019. http://www.who.int/medicines/services/essmedicines_def/en/

2 Persaud N, Jiang M, Shaikh R. Comparison of essential medicines Lists in 137 countries. Bull World Health Organ 2019;97:394-404.

3 World Bank Blogs. New country classifications by income level: 2019-2020, 2019. Available: https://blogs.worldbank.org/opendata/ new-country-classifications-income-level-2019-2020 [Accessed 17 Jul 2019].

4 Chow CK, Ramasundarahettige C, Hu W, et al. Availability and affordability of essential medicines for diabetes across highincome, middle-income, and low-income countries: a prospective epidemiological study. Lancet Diabetes Endocrinol 2018;6:798-808.

5 Duong M, Moles RJ, Chaar B, et al. Essential medicines in a high income country: essential to whom? PLoS One 2015;10:e0143654.

6 Wirtz VJ, Hogerzeil HV, Gray AL, et al. Essential medicines for universal health coverage. Lancet 2017;389:403-76.

7 Patented Medicine Prices Review Board. Annual report 2017. Available: https://www.pmprb-cepmb.gc.ca/CMFiles/Publications/ Annual\%20Reports/2018/2017_Annual_Report_Final_EN.pdf [Accessed 15 May 2020].

8 Law MR, Cheng L, Dhalla IA, et al. The effect of cost on adherence to prescription medications in Canada. CMAJ 2012;184:297-302.

9 World Health Organization. Global health observatory (GHO) data. Geneva, 2018. http://www.who.int/gho/en/

10 Central Intelligence Agency. The world factbook, 2019. https://www. cia.gov/library/publications/the-world-factbook/

11 The World Bank. GNI per capita, Atlas method (current US\$), 2019. Available: https://data.worldbank.org/indicator/NY.GNP.PCAP.CD? end=2018\&most_recent_value_desc=true\&start=1962\&view=chart [Accessed 17 Jul 2019].

12 GBD 2015 Healthcare Access and Quality Collaborators. Electronic address: cjlm@uw.edu. Healthcare access and quality index based 
on mortality from causes amenable to personal health care in 195 countries and territories, 1990-2015: a novel analysis from the global burden of disease study 2015. Lancet 2017;390:231-66.

13 WHO. Model Lists of essential medicines. Geneva: World Health Organization, 2017. https://www.who.int/medicines/publications/ essentialmedicines/en/

14 Charles O, Onakpoya I, Benipal S, et al. Withdrawn medicines included in the essential medicines Lists of 136 countries. PLoS One 2019;14:e0225429.

15 European Medicines Agency. Forxiga, 2020. Available: https://www. ema.europa.eu/en/medicines/human/EPAR/forxiga [Accessed 15 May 2020].

16 European Medicines Agency. Pradaxa, 2020. Available: https://www. ema.europa.eu/en/medicines/human/EPAR/pradaxa [Accessed 15 May 2020].

17 Zelniker TA, Wiviott SD, Raz I, et al. Sglt2 inhibitors for primary and secondary prevention of cardiovascular and renal outcomes in type 2 diabetes: a systematic review and meta-analysis of cardiovascular outcome trials. Lancet 2019;393:31-9.

18 World Health Organization. Model list of essential medicines, 21st list. Geneva, 2019. https://apps.who.int/iris/bitstream/handle/10665/ 325771/WHO-MVP-EMP-IAU-2019.06-eng.pdf?ua=1
19 Julia S, James U. Direct oral anticoagulants: a quick guide. Eur Cardiol 2017;12:40.

20 World Health Organization. Palau pharmaceutical country profile. Available: https://www.who.int/medicines/areas/coordination/Palau_ PSCP_NarrativeFeb18.pdf?ua=1 [Accessed Sept 2012].

21 World Health Organization. Oman pharmaceutical country profile. Available: https://www.who.int/medicines/areas/coordination/ OmanPSCP_Narrative2012-02-08-Final.pdf?ua=1 [Accessed Sept 2012].

22 European Commission. State of health in the EU - Sweden country health profile, 2019. Available: https://ec.europa.eu/health/sites/ health/files/state/docs/2019_chp_sv_english.pdf

23 Eriksen J, Gustafsson LL, Ateva K, et al. High adherence to the 'wise list' treatment recommendations in Stockholm: a 15-year retrospective review of a multifaceted approach promoting rational use of medicines. BMJ Open 2017;7:e014345.

24 Spurling GK, Mansfield PR, Montgomery BD, et al. Information from pharmaceutical companies and the quality, quantity, and cost of physicians' prescribing: a systematic review. PLoS Med 2010;7:e1000352. 